\title{
Discussion on the Employee Motivation
}

\section{Qiya Wang}

Economic Management Department, North China Electric Power University, Hebei, China

\section{Email address:}

2334397088@qq.com

\section{To cite this article:}

Qiya Wang. Discussion on the Employee Motivation. Journal of Finance and Accounting. Vol. 4, No. 2, 2016, pp. 47-51. doi: $10.11648 /$ j.jfa.20160402.13

Received: February 19, 2016; Accepted: March 21, 2016; Published: March 25, 2016

\begin{abstract}
With the development of market economy in our country, catering business has become very important in the industry of our country's economy. The development of enterprises in the food process, the personnel have become increasingly prominent. Human Resources have become a key factor in the healthy development of the company. Employees are the core strength of catering enterprises. Enthusiasm and creativity of the staff directly determines the level of quality of service. If you want to achieve sustainable development, the key is to attract and retain good employees. So an effective incentive to impose the measures to fully mobilize their enthusiasm is the key. Desheng Hotel, is a main restaurant, leisure, entertainment, accommodation, food, supplemented by medium-sized enterprises, by the senior management, professional and technical staff, front desk personnel and logistics management and other types of staff. Able to provide food and beverage, entertainment, rest and so comprehensive, high quality train services. As market competition becomes more intense, a change in business efficiency, "brain drain" faster, "talent shortage" is serious. Currently, the development of rational and efficient incentives for employees Bauhinia Hotel is crucial, and urgent.
\end{abstract}

Keywords: Catering Business, Staff, Incentive

\section{Introduction}

Since the reform and opening policy, catering enterprises as a traditional service industry in the tertiary industry in our country, the development which progresses by leaps and bounds, the position and role in national economy improved remarkably. However, with the expanding of opening to the outside world, the domestic enterprises to join, catering enterprises competition is growing. Some medium-sized catering enterprises lack scientific human resources management mechanism, which cause a "talent shortage" phenomenon. Employee motivation become new problems enterprise faces. Simply speaking, the incentive is to meet the needs of the catering enterprises employees and make they work hard, so as to realize the process of organizational goals. This seemingly simple, but the execution is not. Catering enterprises is a traditional industry. Processing equipment technology content is low; Capacitance operation, investment is not high; what's more the government face the pressure of employment, makes the restaurant threshold very low. This creates a catering business decisions or management personnel quality is uneven, so it is difficult to make a scientific incentive measures.

At present, China's catering industry are widespread "talent shortage", "talent shortage" can be simply summarized as fundamental: hiring, retention of choose and employ persons, difficult. It has become obstacles to the whole industry development, the establishment of the main bottleneck of high quality and high level service team. Core reason for this phenomenon is the lack of reasonable competitive incentives. The rapid development of China's catering industry needs advanced incentive system support, which could attract talents, retain talents, set up a good staff for the company, only in this way can ensure the realization of the company's business goals and strategic objectives.

\section{Research Meaning and Purpose}

From the perspective of the theory exploration, the incentive theory and research in western developed countries have a long history. Many famous incentive theory of famous experts and incentive theory emerged in that time. The traditional incentive theory research put employees as individuals research, lack of pertinence, at the same time our country is different from western developed countries, 
different economic, social and cultural background gives new meaning of this research in our country.

From the perspective of the actual situation of China, private enterprises is developed in the cracks of national policy; And the opening of the 16th national congress of the CPC, paving the way for the development of private enterprises; With unprecedented speed rapid development, however, the private enterprise is too young to standard sound system, to retain and use good talent has become a big problem. So it is especially meaningful in private enterprise that incentive mechanism should be established in order to retain and use good talent for the enterprise to provide the feasibility of ideas.

Besides through the study of hotel staff incentive mechanism, I can check the degree which I absorb theory knowledge of business management courses, to further improve the ability to apply the theory, analyze and solve problems.

\section{The Research Status at Home and Abroad}

In 1933, Mayo and others through hawthorne experiment for the first time puts forward the viewpoint that enterprise employees is "social people" [1]. That an organization should be given with high productivity and job satisfaction of workers. In order to better survival and development, enterprise employees is "social person". The experiment opened for job satisfaction research in modem times, and provides a basic introduction for the further development of incentive theory.

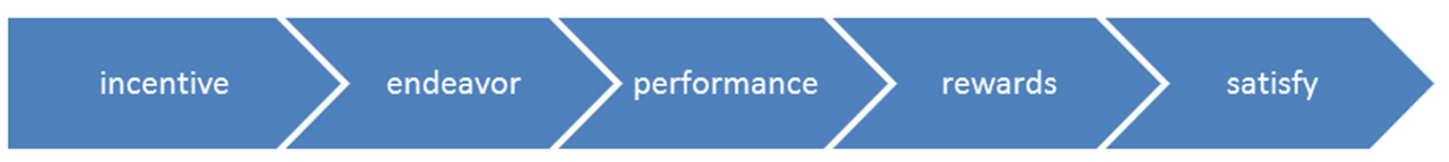

Fig. 1. Model of Comprehensive Encouragement.

In 1963, Adams put forward fair theory, and he thinks that the generation of job satisfaction not only comes from the staff from your work, but also what more important is to see their earnings and compared the results of the others [2]. Maslow puts forward the famous idea of hierarchy needs. It is thought that the people of a variety of needs can be classified into five levels: physiological needs, security needs, social needs, respect needs and self-actualization needs. Only meet the needs of employees step by step, can achieve a good incentive effect.

The late United States Stephen p. Robbins integrated the above theory to build the integrated incentive model.

The model formed the "incentive - endeavor - performance rewards - satisfy" and efforts from satisfied feedback to such a virtuous circle.

Today there are quite a realistic guiding significance. Foreign motivation theory has its own system, many domestic scholars only localization based on the results of foreign incentive theory to the small branches. Huang Jiang and others study that different enterprise significant differences on the satisfaction condition: foreign enterprises $>$ private enterprises $>$ state-owned enterprises. Put forward the reform of the state-owned enterprises. Chongming wang, Jianjie wang analyzed the difference of the profession by transverse comparison earliest, analysis of the mental work satisfaction level is generally higher than that of manual labor, which still did not get rid of the material factors. Can be seen that although the domestic study has made valuable exploration for the employee satisfaction, but there are still insufficient in research. Most of the study is in default under the consistent state, did not consider situational factors, such as political, economic, social and cultural background differences. In research method, it is not a dynamic method, lack of the analysis of the factors; Research field, compared with foreign, domestic empirical study of job satisfaction is relatively sufficient, repeated labor in the majority. Therefore, we should further expand the incentive theory in the field of applied research, strengthen the operational level, achieve its guiding significance and application value of the organization's management practice [3].

\section{The Main Problems and Analysis}

\subsection{Without Getting to Know the Needs of the Employees}

Hotel as for-profit companies are too focused on corporate profits. Ignored the nature of employee needs, and just pay attention to the customer's feelings. Managers didn't realize employee satisfaction, providing customers with satisfactory service. Without timely communication with employees, the interests of the employees and the hotel points have some differences, leading to a fall in group cohesion. Because the communication between hotel managers and staff are less, many employees reflect lack of the company "atmosphere" feeling; many employees can't understand the company's development strategy and the practice of senior. They also feel bad about the prospect of the enterprise, so many embarrassing situation occured. Any enterprise with only good intentions and enthusiasm is not enough. It must also have unimpeded information communication and emotional communication, and understand employee needs.

\subsection{The Material and Spiritual Incentive Double Lack}

Defects in hotel incentive system also behave inbanlence between material incentive and spiritual incentive. Does not consider the multiple needs of employees. Regardless of their level, only given material incentives, caused the marginal effect of incentives diminishing year by year. Managers blame employees too much needs and employees complain that incentive is too drab. Although enterprise carry on the 
incentives time-consuming, the incentive effect are not so good. Therefore, carry on the incentives must be the combination of material incentive and spiritual incentive, diversified in form. So it can be achieved to maximize incentive effects. At present, the hotel human resources incentive in mental health problems lack of diversity and focus too paranoid. In honor or promotion, the enterprise pay attention to age and formal schooling. While some actual work ability is higher and have made outstanding contribution to employees, didn't get the satisfaction of spirit. It must weaken some employees work enthusiasm, and is not conducive to its role in comprehensive incentive.

\subsection{Lack of Attention to Enterprise Culture}

The hotel pursuit of value, benefit, lack of attention to enterprise culture construction. Enterprises lack the spirit of which can let employees strive forward and make employee and enterprise tightly hold. If people can not see the bright future of the enterprise, the talented person will be difficult to stay. Enterprise managers often ignore the incentive effect of the environment, just simply think environment is the external factor, and the impact on the employee is not big. The idea for the future of their employee's departure planted hidden dangers. What we call the motivation mainly include the enterprise culture environment and objective working environment two categories.

\section{Solutions and Suggestion}

\subsection{Insist on the Principle of Combination Material Incentive and Spiritual Incentive}

\subsubsection{Build a Reasonable Salary Incentive System}

For the existing problems of compensation system, combination various forms of compensation should be taken to form a perfect salary distribution system. Reasonable and effective compensation system is complete salary system, including economic compensation and the non-economic salary, mainly include basic salary, the fixed bonus, mandatory hotel contribution, voluntary contribution, special allowance funds, and long-term service. For these forms of compensation, a hotel can use integrated and flexible, formed effective compensation combination system [4]. In addition, the compensation system still take the wage structure, employee's basic pay consists of the basic salary, post salary, performance salary, degree of wages, subsidies.

The basic salary plus post salary and seniority pay should not under the city's minimum wage standard. It should be dominated by performance-related pay and subsidies should be proper and manifests the enterprise the care.

\subsubsection{Meet the Demand of Employees in the Spirit of Entertainment}

Managers should pay great attention to the needs of the staff, and realize that meeting the needs of the employee is a basic prerequisite to mobilize the enthusiasm of the employees. When the basic material needs satisfied, meet the demand of employees spirit becoming crucial. Communication has a lot of problems in restaurants. If managers can timely observe, communicate with employees active and openly, and listen to your employees, can stimulate the staff's sense of belonging. The opinions of the staff get attention, so they natural have relaxed mood. Communication mechanism changed the relationship between the staff and the hotel, enhance the employees the sense of responsibility, and arise the spiritual incentive. According to maslow's demand theory, the demand of people is a multi-level [5]. Despite hotel employees have the low level of culture, but also have its strong spiritual needs, mainly displays in improving their own ability and the culture. To strengthen training under this demand becomes very necessary. Make staff full of confidence, trust employees is a very effective incentive method. Trust is a acception for intelligence and creativity of the employees, can arouse the staff's sense of responsibility and a sense of pride. Employees get trust and easier in the work, so they can provide better service to the guests, and win the guest satisfaction.

\subsection{Insist on the Principle of Fair and Just}

\subsubsection{Establish the Inspection Rewards and Punishment System}

Fairness is the basic principles of incentive. Everyone would compared their pay and contribution ratio with others, whether their treatment is the fair. When the basic salary under the condition of flat, good staff should be given a certain reward, the reward include material rewards such as bonuses, prizes, and spiritual rewards such as certificate, honorary title, public praise and so on. Similarly, for the employees of poor performance without a little punishment is unfair for other employees, easy to hit the enthusiasm of other employees. But that should be paid attention to is the punishment should be appropriate for the principle, such as a small amount of fine, criticism, education. But it can't hurt employees dignity, also ensure the employee's basic life.

\subsubsection{Combined with Post Evaluation and Performance-Related Pay}

Post assessment is the foundation of compensation system design. It focuses on solving the problem of the salary fairness inside [6]. With the actual situation of the hotel elements point method should be applied in estimating position evaluation. Specific elements including job performance, job responsibilities, knowledge, skills and working conditions four aspects. Which position is different, compensation accordingly; High skill employees should be accordingly higher wages; Hard working conditions of staff should get higher subsidies. Performance should be emphasized in this four elements. According to the actual situation of the hotel, we can take two forms salary system. Firstly, combine the performance salary with personal performance on the job, still connected to the hotel economic benefits. Namely the performance salary issued by the completion of the revenues and profits for enterprise; secondly, the staff of the performance-related pay is not linked to the economic benefits of hotel, the issuance of the performance salary based on 
individual performance appraisal results.

\subsubsection{Establish Fair Promotion Mechanism}

Internal fairness not only refers to pay fair, also including fair promotion mechanism. Promotion should consider length of working age, work performance, education degree, ability to size, etc. Establishing healthy competition environment in the enterprise can make employees grow up. Enterprises promote talent, must know its expertise, then expertise needed for each position to the right post which need a certain talent configuration. Avoid "bigto small use" also want to avoid "small to use" [7]. Internal promotion system not only guarantee the source of a lot of talent, but also the most effective incentive policy. So promotion channels must be notarized, transparent, otherwise it will unfair to bring more negative effect.

\subsection{Build Good Corporate Culture}

\subsubsection{Adhere to the "People-Oriented"}

Modern staff with modern thinking and life, the hotel must adopt the idea of humanization management, and adhere to the "people-oriented" principle in the management [8]. "People-oriented" has many ways in the concrete practice, attaching importance to employee's family is very important. The families of the workers is behind the pillar of the employees. When employees get the praise, give employees a home for carmakers. When in holidays, make a greeting to the employee's home. These are easy, but fully embodies the humanistic care of the hotel. It is worth mentioning that incentive is ubiquitous. Incentives should be embodied in the daily life of dribs and drabs, giving employees a word of praise, a small gift. Making friends with them, caring about their life and emotion, let employees feel unit is a home, not just a place to work.

\subsubsection{Manage Harmonious Employee Relationship}

There are many factors that can influence the development of the enterprise, but is nothing more than inductive, geographical and human conditions. Among them, human conditions is the most precious. If there are no people, operator and staff disputes constantly, enterprise leadership, higher and lower levels, departments of the department finds over trifling, will miss a good opportunity [9]. Good interpersonal and group atmosphere is a hotbed of effectively motivate employees. Harmonious working environment is a important reason for the staff is willing to work for a long time. Make the atmosphere of happiness is not difficult to set up some entertainment activities. Managers treat people generous, reasonable solutions to the disputes are good.

\subsubsection{Build Morale Boost Culture}

To make it clear to the hotel staff, his job is glorious, and serve the people is happy, own enterprise is excellent [10]. If you can mind this view, it will certainly bring huge incentive effect. In particular, we can adopt the following practices with slogans inspire morale. Make a song belong to a hotel enterprise, making enterprise culture spread. Do a business publications that employees can writing own articles involved, etc. The so-called culture refers to the hotel staff values, beliefs, attitudes and habits of fusion, need to accumulate over a long period, from small things to cultivate, and directly rooted in the minds of hotel staff.

\section{Conclusion}

Catering enterprises in our country is a perfectly competitive industry with huge market and lower trade barriers. With the development of market economy in our country, catering enterprises as one of the highest degree of marketization industry, can not be ignored in the industry of our country's economy. But the human resources of the current state of the catering industry in our country is worrying. Food industry employees have lower cultural quality, and the volume is big. In the face of these difficulties, the enterprise must come up with a set of scientific staff incentive schemes, and strictly enforced. Without geting a catering enterprise employees incentive work will make employees work enthusiasm, resulting in the loss of talent, enterprise internal chaos, a divided. It will directly affect the enterprise's development and benefit. On the contrary, successful incentive strategies may be needed to attract and retain the business of various levels of talents, and make they put positive efforts to work. So what should be fully awared is that as an important part of the third industry of the important position of the restaurant industry in the national economy construction, realize the importance of staff in the catering enterprises, realize the consequences of work incentive for employees to influence. Establish a set of enterprise staff incentive system suitable for their own enterprise development, and scientific to apply, which is good at the development and expansion of catering enterprises.

In conclution, this paper analyzes employee motivation based on the way of communication, motivation, enterprise culture environment, and puts forward some effective Suggestions and specific solutions. Hope for the city's hotel refere the effective incentive method. To optimize the internal personnel configuration, improve staff enthusiasm, and improve the efficiency of the hotel management. Eventually make the hotel to get stable, persistent, and good development.

\section{Acknowledgements}

At the point of finishing this paper, I'd like to express my sincere thanks to all those who have lent me hands in the course of my writing this paper. First of all, I'd like to take this opportunity to show my sincere gratitude to my teacher in charge, who has given me so much useful advices on my writing, and has tried her best to improve my paper. Secondly, I'd like to express my gratitude to my classmates who offered me references and information on time. Last but not the least, I'd like to thank those leaders, teachers and working staff especially those in the School. Without their help, it would be much harder for me to finish my study and this paper. 


\section{References}

[1] Xiao-yan wang: how to incentive employees, Peking University press, 2005. 7.

[2] Jiaqiang Li: employee motivation - 16 kinds of effective employee incentive method, and the line management consultant, 2004.3.

[3] Shaopeng Zhang: shallow theory of knowledge staff motivation, Chinese BBS management, 2003. 6.

[4] V. H. Vroom and P. W. Yetton. Leadership and Decision Making Pittburgh. University of Pittsburgh Press, 1 973, 1 0(2): 45-5 1 .

[5] Gui-jun zhuang, Youlian zhou, gui-lin wang. Staff incentive system [M]. Version 1. Beijing: Peking University press, 2004.

[7] Yingyu Zhou. Employees' incentive system and management [M]. 3rd edition. Beijing: China economic publishing house, 2003.

[8] Fang-hua wang, jun-fang xi. Employee motivation [M]. Second edition. Shanghai: Shanghai jiaotong university press, 2003.

[9] Wang yu. China's state-owned enterprises staff incentive countermeasures study [J]. Journal of economic news, 2006 (5): $23 \sim 25$.

[10] Xu Hong Huang Qindong. Learn to effective authorization. Business. 2005. 9: 78-79.

[11] Xin-bo sun, zhi-ping fan, Qin Erdong. Employee incentive theory and practical knowledge. Economic management press, 2006. 12.

[12] Jun-yong liu, sun wei editor. Enterprise performance evaluation and incentive mechanism. Beijing: China citic press. 2007. 6.

[6] Lu Lin. Employees' incentive system [M]. 3rd edition. Beijing: the capital university of economics and trade publishing house, 2002. 